\title{
CONCEPÇÕES DE LINGUAGEM NO LIVRO PARADIDÁTICO: A LEI 5692/71 E A LÍNGUA PORTUGUESA COMO COMUNICAÇÃO E EXPRESSÃO
}

Rosana Aparecida de Mello Garcia Doutoranda em Linguística pela Universidade Federal de Santa Catarina (PPGLin/UFSC) rosanagarcia@ifsc.edu.br

\section{RESUMO}

A promulgação da Lei de Diretrizes e Bases da Educação (LDB) de 1971, Lei 5692/71, resultou em profundas mudanças no sistema educacional brasileiro, ao estabelecer que os objetivos da educação seriam direcionados para as necessidades do mercado de trabalho e os currículos passariam a dar ênfase ao ensino tecnicista e profissionalizante no ensino de 10 e 20 graus. $O$ objetivo deste estudo é analisar as concepções de linguagem no livro paradidático Comunicação $e$ Expressão Através do Conto e Crônica, que fazia parte das referências dos planos de ensino da ETEFESC sob a vigência da Lei $5692 / 71$. Este estudo apoia-se nas noções de Bakhtin sobre linguagem, enunciado, dialogismo e gênero do discurso, e nos princípios teórico-metodológicos da Análise Dialógica do Discurso. O livro analisado apresenta a concepção de linguagem como instrumento de comunicação, dialogando com a Teoria da Comunicação e as leis e normas daquele período.

Palavras-chave: espaço, memória, natureza, opção identitária.

\section{ABSTRACT}

The implementation of the Diretrizes e Bases da Educação (LDB) legislation of 1971, Law 5692/71, resulted in profound changes to the Brazilian educational system as it established that the objectives of education would be directed to the needs of the job market and the curriculums would begin to stress technical and professional aspects in Lower School through High School. The aim of this study is to analyze the language concepts in the paradidactic book Comunicação e Expressão Através do Conto e Crônica which were part of the reference work in Teaching Plans for ETEFESC under the 5692/71 law. This study relies on Bakhtin's concepts about language, enunciation, dialogism and speech genres, as well as the main methodological theories of Dialogical Discourse Analysis. The book in question presents the concept of language as an instrument of communication, as it engages with the Theory of Communication and the laws and norms of that period.

Keywords: space, memory, nature, identity choice. 


\section{Introdução}

A promulgação da Lei de Diretrizes e Bases da Educação (LDB) 5692/71 resultou em profundas mudanças no sistema educacional brasileiro, ao estabelecer que os objetivos da educação seriam direcionados para as necessidades do mercado de trabalho e os currículos passariam apresentar duas partes distintas: a "educação geral" e a "formação especial". A formação especial referia-se à preparação para o trabalho, na forma de iniciação no 10 grau e habilitação profissional no $2^{\circ}$ grau.

Sob a vigência dessa LDB, o ensino de língua portuguesa passou por grandes transformações, entre as quais, a noção de língua como sistema começou a ser superada pela concepção de comunicação, cujo aporte teórico veio da Teoria da Comunicação.

A própria denominação da disciplina foi alterada, passando a Comunicação e Expressão, nas séries iniciais do 1ำ grau e Comunicação em Língua Portuguesa nas séries finais desse grau. No 2o grau a disciplina passa a se denominar Língua Portuguesa e Literatura Brasileira (SOARES, 2004, p. 169).

A Escola Técnica Federal de Santa Catarina - ETEFESC, atualmente Instituto Federal de Santa Catarina - IFSC, localizada na capital do Estado, precisou adaptar os currículos de seus cursos à nova LDB, e essa adaptação passava pela escolha de livros escolares que dessem conta das necessidades dos cursos e que atendessem às orientações normativas.

Com o propósito de investigar como a instituição de ensino acatou as mudanças previstas, procuramos identificar livros escolares listados como referências pelos professores para as aulas de Língua Portuguesa sob a vigência da Lei 5692/1971. Tomamos por base o programa de ensino do Curso Técnico de Eletrotécnica para 1982, 
no qual encontramos treze referências bibliográficas para a disciplina de Língua Portuguesa e Literatura Brasileira e sete referências para a disciplina de Redação e Expressão em Português. Dos treze livros do primeiro programa, sete eram livros didáticos, cinco eram de referência e um paradidático. No segundo programa, constavam cinco livros de referência, um livro didático e um paradidático.

O livro Comunicação e Expressão Através do Conto e Crônica foi o único livro paradidático recomendado nos dois programas de ensino. Sua autora, Maria de Lourdes Ramos Krieger, era professora da ETEFESC nessa época e escreveu a obra após a promulgação da LDB de 1971. Esses aspectos nos estimularam a investigar quais as concepções de linguagem assumidas pela autora para o ensino e aprendizagem de língua portuguesa naquele período, diante das mudanças no ensino da língua materna.

O livro paradidático é um livro complementar aos livros didáticos, que "tem por função resumir, intensificar ou aprofundar conteúdos específicos do currículo de uma disciplina", seja por meio de uma utilização individual, em casa, seja como ocorre no Brasil, por meio de uma utilização orientada pelo professor, na escola (ROJO, 2005, p. 15). Ele também apresenta como característica uma maior dinamicidade, pois leva com mais rapidez à escola alguns temas de seu interesse, e, devido a suas características editoriais, pode abordar temas que levariam anos para serem abordados num livro didático (MUNAKATA, 1997, p. 160).

O objetivo deste estudo é analisar as concepções de linguagem nas atividades propostas pela autora do livro paradidático Comunicação e Expressão Através do Conto e Crônica, usado como referência nas disciplinas de Língua Portuguesa e Literatura Brasileira, assim como Redação e Expressão em Português na ETEFESC sob a vigência da Lei $5692 / 71$. 
Para o desenvolvimento da análise, esta deverá ter como base o estudo das concepções de linguagem na obra, pois como lembra Geraldi,

as concepções de linguagem é que embasam o trabalho pedagógico que fazemos no ensino de qualquer das facetas do uso ou da descrição de uma língua. Enquanto essa concepção não for assumida como própria, qualquer que ela seja [...], as atividades não serão geridas pelo professor, mas repetidas por ele como uma rotina, sem construir uma prática verdadeira (GERALDI, 2016, p. 180).

Para a análise do livro, este estudo apoia-se nas noções de Bakhtin sobre linguagem, enunciado e gênero do discurso e nos princípios teórico-metodológicos da Análise Dialógica do Discurso.

O artigo é apresentado da seguinte forma: inicialmente fazemos uma revisão sobre as concepções de linguagem, e, em seguida, analisamos as atividades do livro Comunicação e Expressão Através do Conto e Crônica.

\section{Concepções de linguagem}

A educação é uma prática social que reflete, historicamente, a ação dos sujeitos sobre o mundo. No processo histórico da educação, segundo Geraldi (2006, p. 40), as diferentes iniciativas educacionais respondem a concepções de mundo, a concepções de homem e aos interesses específicos de determinada formação social. O ensino de Língua Portuguesa ampara-se em concepções de linguagem que se constituem nesse processo histórico, assim, 
[...] antes de qualquer consideração específica sobre a atividade de sala de aula, é preciso que se tenha presente que toda e qualquer metodologia de ensino articula uma opção política - que envolve uma teoria da compreensão e interpretação da realidade - com os mecanismos utilizados em sala de aula (GERALDI, 2006, p. 40).

Para Geraldi (2006, p. 41), fundamentalmente, três concepções de linguagem podem ser apontadas: a linguagem como expressão do pensamento, a linguagem como instrumento de comunicação e a linguagem como forma de interação. Essas concepções correspondem às três grandes correntes dos estudos linguísticos: a gramática tradicional; o estruturalismo e o transformacionalismo; e a linguística da enunciação.

\section{Ensino tradicional: a linguagem é a expressão do pensamento}

Esta concepção de linguagem é associada ao ensino tradicional e é orientada pela psicologia individual, na qual "a capacidade de o homem organizar de maneira lógica seu pensamento dependerá da exteriorização desse pensamento por meio de uma linguagem articulada e organizada" (TRAVAGLIA, 1997, p. 21).

Até o final da década de 1960, o ensino tradicional previa o ensino da Língua Portuguesa, a partir da "noção de língua como sistema" (SOARES, 2004, p. 169). O ensino de língua se baseava na listagem de nomenclaturas, geralmente voltadas para aspectos morfossintáticos. Nas raras situações em que o texto, prioritariamente literário, era abordado em sala, voltava-se sua abordagem para as questões de compreensão, sem que os alunos tivessem maior contato com suas condições de produção e recepção. O ensino de redação, ainda hoje muito praticado nas salas de aula de ensino fundamental e médio consiste principalmente em ensinar a tipologia textual: narração, descrição e dissertação. 
Segundo Bonini (2002, p. 27), "a base de reflexão era a teoria tradicional da gramática, apoiada nas técnicas da retórica clássica. De postura prescritivista, pautava-se pela aplicação de regras do bem-escrever". Nessa concepção, o ensino de língua enfatiza a gramática teórico-normativa: conceituar, classificar, para, sobretudo, entender e seguir as prescrições - em relação à concordância, à regência, à acentuação, à pontuação, ao uso ortográfico.

\section{Estruturalismo e teoria da comunicação: a linguagem é instrumento de comunicação}

Nesta concepção, a língua é vista como um código, ou seja, "um conjunto de signos que se combinam segundo regras e que é capaz de transmitir uma mensagem, informações de um emissor a um receptor" (TRAVAGLIA, 1997, p. 22), conceito este, ligado à Teoria da Comunicação. Outras influências desta concepção são o Estruturalismo e o Gerativismo.

Na escola, sob a influência da Teoria da Comunicação, "os objetivos passam a ser pragmáticos e utilitários: trata-se de desenvolver e aperfeiçoar os comportamentos do aluno como emissor e recebedor de mensagens, através da utilização e compreensão de códigos diversos - verbais e não verbais" (SOARES, 2004, p. 169).

Nesse período, os textos escolares já não são escolhidos exclusivamente a partir de obras literárias. A leitura passa a incluir textos não-verbais e a linguagem oral "volta a ser valorizada, mas agora para a comunicação no cotidiano - pela primeira vez aparecem em livros didáticos de língua portuguesa exercícios de desenvolvimento da linguagem oral em seus usos cotidianos (SOARES, 2004, p. 170). 
O estudo do texto tinha como princípio o desenvolvimento das habilidades de leitura, integrado ao "desenvolvimento das habilidades de ouvir, falar e escrever e a aquisição de conhecimentos de gramática" (SOARES et al., 1979, p. 38), porém, segundo Koch e Elias (2012, p. 10), o texto passou a ser visto como simples produto da codificação de um emissor a ser decodificado pelo leitor/ouvinte, bastando a este, para tanto, o conhecimento do código utilizado.

\title{
4. Interação discursiva: a linguagem como forma de interação
}

\author{
Nesta concepção, a linguagem é
}

um lugar de interação humana, de interação comunicativa pela produção de efeitos de sentido entre interlocutores, em uma dada situação de comunicação e em um contexto sócio-histórico e ideológico [...] esta concepção também é conhecida como linguística da enunciação, e é representada por várias correntes e teorias, como a linguística textual, a teoria do discurso, a análise do discurso, a análise da conversação, a semântica argumentativa e todos os estudos de alguma forma ligados à pragmática (TRAVAGLIA, 1997, p. 23).

Desenvolveremos alguns conceitos da concepção de linguagem como forma de interação concebidos pelo Círculo de Bakhtin, para quem a realidade fundamental da língua "é o acontecimento social da interação discursiva que ocorre por meio de um ou de vários enunciados" (VOLÓCHINOV, 2017 [1929], p. 219). Assim, a linguagem compreendida como discurso não pode ser dissociada das relações entre os falantes e das esferas sociais em que atuam. 
O dialogismo é um conceito fundamental do pensamento de Bakhtin, o "princípio unificador da obra" (FIORIN, 2006, p. 18), que funda sua concepção de linguagem e se refere às relações de sentido que se estabelecem entre dois enunciados. A abordagem dialógica proposta por Bakhtin objetiva "compreender a constituição e o funcionamento dos gêneros a partir de sua relação com a situação social de interação dentro de uma esfera social de atividade" (ACOSTA-PEREIRA; RODRIGUES, 2009, p. 11).

A noção de gêneros do discurso leva em conta que a utilização da língua se realiza na forma de enunciados produzidos pelos integrantes das diversas esferas da atividade humana e que cada esfera de utilização da língua "elabora seus tipos relativamente estáveis de enunciados, os quais denominamos gêneros do discurso" (BAKHTIN, 2011 [1979], p. 261-262).

Novas situações de interação social propiciam o surgimento de novos gêneros, que se constituem e se estabilizam no interior de uma determinada esfera discursiva, como ocorreu com o livro paradidático, que é um gênero escolar.

\section{Análise do livro paradidático Comunicação e expressão através do conto e crônica}

A análise das concepções de linguagem no livro Comunicação e Expressão Através do Conto e Crônica se apoia na perspectiva dialógica do discurso, que segue orientações epistemológicas da Análise Dialógica do Discurso. Nessa análise, não há categorias a priori, que possam ser aplicadas de forma mecânica a textos e discursos, com a finalidade de compreender formas de produção de sentido no texto. O foco da análise são os elementos constitutivos do discurso que apontam para os modos de discursivização, examinando as regularidades materializadas no discurso (ROHLING, 2014, p. 47). 
O livro paradidático Comunicação e Expressão Através do Conto e Crônica, de Maria de Lourdes Ramos Krieger, foi publicado pela Editora Lunardelli, em Florianópolis/SC, em 1976, com 55 páginas.

A apresentação do livro Comunicação e Expressão Através do Conto e Crônica é redigida em duas seções, uma delas para os professores e a outra para os alunos. A apresentação dedicada aos professores é feita pela autora, momento este em que ela se dirige aos professores de Comunicação e Expressão e explicita parte de seu projeto de dizer. Na apresentação do livro dedicada aos alunos, a posição de autoria é ocupada pela Editora, que funciona como um "autor interposto" (RODRIGUES, 2001, p. 164-165), de modo que "sustenta" o ponto de vista da autora, e funciona como credenciadora do seu discurso.

Os interlocutores previstos são os professores e os alunos das últimas séries do 1은 grau (7ạ e 8aㅗ ) e primeira série do $2^{\circ}$ grau, incluindo também, totalmente integrados ao contexto da época, os estudantes de cursos profissionalizantes, contemplados pela Lei 5692/71 nesses níveis de ensino.

O livro é composto por sete crônicas e dois contos de escritores catarinenses. O gênero conto, produzido no interior do campo literário, é configurado como uma narrativa pouco extensa onde a história se desenvolve linearmente, com princípio, meio e fim, "que tem como característica central condensar conflito, tempo, espaço e reduzir o número de personagens" (GANCHO, 1991, p. 8). Já a crônica, "por se tratar de um texto híbrido, nem sempre apresenta uma narrativa completa; uma crônica pode contar, comentar, descrever, analisar. De qualquer forma, as características distintivas da crônica são: texto curto, leve, que geralmente aborda temas do cotidiano" (GANCHO, 1991, p. 8). 
A cada nova crônica ou conto, a autora apresenta uma pequena biografia de seus autores e também formula um breve comentário, chamando atenção para determinados aspectos do texto. Nessa forma de apresentação, há uma compreensão de que o texto não é apenas lido, mas que ele é "estudado", ou seja, "o estudo dos textos pretende desenvolver habilidades específicas de decodificação, interpretação, inferência, análise e avaliação de mensagens veiculadas pela língua escrita" (SOARES et al., 1979, p. 40).

De acordo com esses autores, há algumas etapas a serem cumpridas para o estudo do texto: a) apresentação do texto, etapa esta que se subdivide em: motivação de estudo e leitura do texto; b) explicação do texto; c) exercícios sobre o texto. Essas etapas estão presentes em todos os textos que fazem parte do livro. A análise do texto é realizada sobre as atividades propostas pela autora.

\section{Análise das atividades}

Na primeira crônica, intitulada "No tempo dos vinténs", de Rachel Meyer, a autora apresenta o texto para o leitor e incentiva o aluno à leitura contínua, tendo atenção às características particulares de cada autor. Assim, pela criação de suas próprias características, poderia aplicá-las nas próprias produções textuais (KRIEGER, 1976). Essa recomendação da autora lembra que os textos de leitura eram considerados estímulos para a escrita.

O segundo texto, "Chora mais quem pode menos", de Cesar Valente, é uma crônica que toma a forma de uma poesia, ou seja, ocorre uma reacentuação de gênero. O texto é escrito na forma de associação livre e aborda temas do cotidiano, referindo-se a notícias 
divulgadas pela imprensa da época, à conjuntura política e à literatura. Para esse texto, a autora propõe onze atividades. Segue um trecho da crônica:

\section{[...] ATCHIM:}

Antigamente era espirro,

Ou código de espião.

Depois virou estrela de comerciais

para coloridos antigripais.

Hoje assusta...

(pode ser meningite!) (VALENTE, 1976, p. 15).

Em Atchim, o autor dialoga com as mídias (cinema, comercial de TV e noticiário). A autora propõe atividades de interpretação e explora esse diálogo com os meios de comunicação para sugerir atividades:

4- O que CV (Cesar Valente) quer dizer quando fala em ATCHIM: “...virou estrela de comerciais/para coloridos antigripais"? [...]

10 - Escolha um destes assuntos para debater com os colegas:

a. Até que ponto os comerciais afetam nossas vidas? (Em ATCHIM temos a sugestão de uma forte influência...) Examinar recortes de jornais e revistas; os produtos anunciados fazem jus à propaganda? [...] (KRIEGER, 1976, p.17).

As atividades têm como foco a propaganda e são voltadas para o desenvolvimento da linguagem oral e escrita em seu uso cotidiano, de forma que são selecionadas "por critérios de intensidade de sua presença nas práticas sociais: textos de jornais e revistas, histórias em quadrinho, publicidade, humor passam a conviver com os textos literários" (SOARES, 2004, p. 170). 
Na crônica "Aluga-se uma casa", de Paulo da Costa Ramos, a autora propõe dividir o texto em partes, procurando identificar início e fim de cada parte. Essa orientação de atividade é retomada em outras atividades, está de acordo com a concepção de língua como meio de comunicação e tem seu fundamento no estruturalismo, de forma que a leitura se torna um ato de decodificação. É um tipo de exercício estrutural sobre as estruturas características que definem os vários tipos de parágrafos, para ensinar as diversas formas de "ordenação e desenvolvimento de parágrafo; ordenação por espaço, por enumeração, por contraste, por causa-consequência, por explicitação" (SOARES et al., 1979, p. 59).

Há também atividades baseadas na gramática reflexiva, que propõem atividades nas quais são focalizados os efeitos de sentido. Esse tipo de atividade pode ser encontrado em:

2 - Explique o sentido da palavra romaria em "Começou a romaria na casa do Meu Amigo".

6 - Explique estas expressões:

“...vêm de ônibus, mau sinal".

"Olham toda a casa, o marido honestamente, a mulher de nariz franzido".

"A alma entregue a Deus...".

7 - Em "Aboletam-se junto ao aparelho", o sentido ficaria diferente se substituíssemos o verbo por Sentaram-se...? Justifique.

8 - Observe as reticências em "Veio ver?..." O que elas nos indicam? (KRIEGER, 1976).

Essa forma de ensino da gramática estava de acordo com a proposta da Lei 5692/71 e da Resolução no 08/71, que orientava "as situações de experiência tenderão a equilibrar-se com os conhecimentos sistemáticos para configuração da aprendizagem", 
assim, "cabe ao professor programar as atividades no sentido de evidenciar o sistema que subjaz ao processo de estruturas linguísticas" (SOARES et al., 1979, p. 59).

A crônica "Quando Chovia", de Jair Francisco Hamms, tem função poética, ainda que não seja escrita na forma de uma poesia: "Quando chovia. Bem, chovia, mudava tudo. Pois que os dias de sol, os dias de sol da minha infância escorreram assim [...]" (HAMMS, 1976, p. 27).

Ao propor as atividades, entre outras, a autora se volta para o estudo de figuras de linguagem, tempos verbais, sinônimos:

[...] 7 - Procure explicar estas expressões: 'O cheiro, o cheiro não, o perfume da terra recém-molhada inundava tudo.' '...pequenas conchas, brancas, dançaricavam ...' '... mil telhas faziam pipi'. '... e uma flor assassinada pelo forte vento...' '...os bordados mal bordados'.

8 - Observe que o autor emprega verbos no imperfeito: mudava, chovia, corria. Ficaria diferente se ele, empregando o perfeito, dissesse: 'Quando choveu, mudou tudo e eu corri para o quarto da vovó'? Em que consiste a diferença? $9-E$ se, ao invés de dizer 'Vovó era obesa', ele escrevesse 'Vovó era gorda'? 10 - Pense em um momento de sua meninice. O que representou poesia? Escreva contando. JFH empregou muitos recursos, para valorizar a crônica. Veja o que mais Ihe agrada e faça o mesmo em seu trabalho (KRIEGER, 1976, p. 30-31).

O estudo dos sinônimos (atividade 9) tem relevância nos exercícios de vocabulário, pois o professor deve trabalhar os exercícios de forma que sejam identificadas as diferenças entre palavras consideradas sinônimas, "para que o aluno perceba que uma palavra não pode ser substituída por um 'sinônimo' sem que se altere o significado da mensagem" (SOARES et al., 1979, p. 48). Assim, o estudo do texto tinha seu foco 
constantemente voltado para o aprendizado baseado na codificação e decodificação de mensagens.

A autora propõe, ao final, a escrita de um texto com função poética e, ao sugerir o uso de recursos, tais como as metáforas, tempos verbais e sinônimos, para valorizar o texto, parte do princípio que esses recursos foram estudados nas atividades propostas anteriormente, assim, o aluno tem condições de escrever seu texto a partir desses exemplos.

$\mathrm{Na}$ crônica seguinte, intitulada "Cotidiano", de Murilo Sebastião Krieger, as atividades se caracterizam por se voltarem para o texto:

1 - Releia os quatro primeiros parágrafos. Dê um título para cada um.

2 - Justifique o título da crônica.

3 - Você pode identificar o lugar em que ocorrem os fatos narrados; faça-o apresentado provas. (Há duas possibilidades).

4 - Indique os sentimentos que dominam as personagens.

5 - Explique este período do primeiro parágrafo: "Executara a parte que lhe coubera naquele dia sem ter a mínima pretensão de entrar para a História". Que distinções você pode estabelecer entre estória - história - História? [...] (KRIEGER, 1976, p. 3637).

São onze exercícios, nos quais, percebe-se que a leitura é uma atividade que exige do leitor o foco no texto, em sua linearidade, com o simples reconhecimento de palavras e ideias e o papel do leitor é o de extrair conteúdo do texto. A leitura de textos no ensino de língua portuguesa como comunicação e expressão pretende "desenvolver habilidades específicas de decodificação, interpretação, inferência, análise e avaliação de mensagens veiculadas pela língua escrita" (SOARES et al., 1979, p. 36). As atividades propostas 
trabalham essas habilidades, que podem servir para a escrita de um relato em moldes semelhantes.

O texto seguinte é um conto fantástico, escrito por Péricles Prade, intitulado "A Dentadura". Ao apresentar o texto, a autora pontua que se trata se um conto fantástico, absurdo. Mesmo assim, apesar da inverossimilhança, apresenta começo, meio e fim. A autora enfatiza a estrutura do conto, para que o aluno tenha elementos para diferenciá-lo da crônica. Em uma atividade, a autora propõe a criação de uma história em quadrinhos ou de um texto:

5 - Você gosta de desenhar? Já experimentou criar uma HQ (História em Quadrinhos)? O conto oferece bom enredo para uma engraçada HQ. Tente! Bem, talvez você não goste de riscos e rabiscos. Não faz mal. Invente um texto. Tão fantástico e absurdo quanto o de PP. Absurdo, sim, mas que tenha começo, meio e um fim surpreendente. Mãos à obra! (KRIEGER, 1976).

As histórias em quadrinhos também faziam parte dos novos textos a serem trabalhados nas aulas de Língua Portuguesa na concepção de língua como instrumento de comunicação. A autora dá a opção ao aluno de criar uma história em quadrinhos ou fazer um texto com a característica do conto, com começo, meio e fim. O livro é finalizado com outro conto, com atividades que seguem os princípios da concepção de linguagem como instrumento de comunicação.

\section{Considerações finais}


A análise do livro Comunicação e Expressão Através do Conto e Crônica foi realizada em seus aspectos gerais como enunciado, com a determinação do contexto de sua publicação, situando-o como enunciado do gênero livro paradidático, examinando a situação de interação, a posição de autoria inscrita no gênero e as concepções de linguagem presentes no livro.

O livro paradidático, como lembra Munakata (1997), é um gênero que consegue integrar-se ao espaço escolar de forma mais rápida, pois não é regulado com o mesmo rigor do livro didático. Por meio dele, existe a possibilidade de que alguns temas sejam introduzidos na esfera escolar antes que outras fontes tratem deles, constituindo-se, assim, um instrumento promissor para as aulas de língua portuguesa. Essa característica ficou bastante evidente na análise do livro Comunicação e Expressão Através do Conto e Crônica, que rapidamente incorporou as propostas de mudança no sistema de ensino e da concepção teórica que emergiam por meio da Lei 5692/71 e suas normas complementares.

$\mathrm{Na}$ análise do livro paradidático Comunicação e Expressão Através do Conto e Crônica, constatamos que a obra apresenta, predominantemente, a concepção de linguagem como instrumento de comunicação. No texto, são encontradas diversas referências à concepção de linguagem que permeia o livro. A autora se identifica como professora de Comunicação e Expressão e tem como interlocutores os professores da mesma área.

O ensino de língua portuguesa na perspectiva da "comunicação e expressão" tinha uma preocupação com a realidade prática, com elementos da comunicação e funções da linguagem e previa uma maior diversidade de gêneros no ensino, inclusive com a 
introdução de gêneros da esfera jornalística e publicitária, porém, reduzindo a presença de textos literários (ROJO, 2013, p. 169).

Essa tendência, no entanto, não inibiu a iniciativa da autora. Com formação na área da literatura, ela opta pelos gêneros literários conto e crônica, que permitem o uso de uma linguagem dinâmica e contemporânea, atendendo aos seus objetivos de apresentar uma obra que auxiliasse nas atividades de leitura, expressão oral e produção textual das aulas de língua portuguesa. A análise do livro deixa transparecer que as atividades propostas aos alunos foram resultado de planejamento bem arquitetado, demonstrando o conhecimento e a vinculação da autora à perspectiva do ensino de língua portuguesa como Comunicação e Expressão e à concepção de linguagem como instrumento de comunicação.

O livro paradidático Comunicação e Expressão Através do Conto e Crônica estava em sintonia com as teorias e as normas educacionais da época, porém coexistia com publicações anteriores à vigência da Lei 5692/71, nos mesmos programas de ensino, indicando que, em momentos de transição, a convivência de diferentes pressupostos sobre o papel da escola, o ensino e a aprendizagem, as relações professor-aluno, as técnicas pedagógicas e concepções de linguagem refletem os movimentos da instituição escolar para fazer frente às mudanças em andamento.

O ensino de língua portuguesa como Comunicação e Expressão contemplava uma abordagem instrumental para o aprendizado da codificação e decodificação de mensagens segundo uma perspectiva formalista, que limitava o estudo ao funcionamento interno da língua, desconsiderando seus aspectos sociais e históricos, porém, final da década de 1980, uma nova concepção de linguagem começou a se estabelecer, a linguagem como forma de interação. Essa nova concepção, aos poucos, foi ganhando 
adeptos nos estudos linguísticos, na linguística textual, na análise do discurso e na sociolinguística, promovendo amplas discussões sobre o ensino e aprendizagem da língua materna. Assim, as mudanças iniciadas com a concepção de língua, como instrumento de comunicação, abriram caminho a reflexões e permitiram que as teorias que emergiam naquele momento histórico pudessem manifestar-se, trazendo consigo novas perspectivas ao ensino de língua portuguesa no país.

\section{Referências}

ACOSTA-PEREIRA, R; RODRIGUES, R. H. Perspectivas atuais de teorias dos gêneros do discurso no campo da Linguística. Letra Magna, ano 5, n. 11, 2o sem. 2009, p. 1-18.

BAKHTIN, M. M. Estética da criação verbal. 6 ed. Tradução de Paulo Bezerra. São Paulo: Martins Fontes, 2011.

BONINI, A. Metodologias do ensino de produção textual: a perspectiva da enunciação e o papel da Psicolinguística. Perspectiva, Florianópolis: UFSC, v. 20, n. 01, jan/jun., 2002, p. 23-47.

BRASIL. Parecer 853/71, de 12/11/1971, do CFE. Núcleo-comum para os currículos de ensino de $1^{\circ}$ e $2^{\circ}$ graus. A doutrina do currículo na lei 5692. Documenta, 132. Rio de Janeiro, novembro de 1971.

FIORIN, J. L. Introdução ao pensamento de Bakhtin. São Paulo: Ática, 2006.

GANCHO, C. V. Como analisar narrativas. São Paulo: Ática, 1991.

GERALDI, J. W. O texto na sala de aula. 4 ed. São Paulo: Ática, 2006.

Dialogia: do discursivo à estrutura sintática. In: RODRIGUES, R. H; PEREIRA, R. A. (Orgs.). Estudos dialógicos da linguagem e pesquisas em linguística aplicada. São Carlos, SP: Pedro e João Editores, 2016. p. 179-189. 
HAMMS, Jair Francisco. Quando chovia. In: KRIEGER, M. L. R. Comunicação e expressão através do conto e crônica. Florianópolis: Lunardelli, 1976. p. 27.

KOCH, I; ELIAS, V. M. Ler e compreender: os sentidos do texto. 3 ed. São Paulo: Contexto, 2012.

KRIEGER, M. L. R. Comunicação e expressão através do conto e crônica. Florianópolis: Lunardelli, 1976.

MUNAKATA, K. Produzindo livros didáticos e paradidáticos. Tese (Doutorado em História e Filosofia da Educação). Pontifícia Universidade Católica. São Paulo: PUC-SP, 1997.

RODRIGUES. R. H. A constituição e funcionamento do gênero jornalístico artigo: cronotopo e dialogismo. Tese (Doutorado em Linguística Aplicada e Estudos da Linguagem - LAEL - PUC-SP). São Paulo: PUC-SP, 2001.

ROHLING, Nívea. A pesquisa qualitativa e análise dialógica do discurso: caminhos possíveis. Cadernos de Linguagem \& Sociedade, v. 15, n. 2, 2014, p. 44-60.

ROJO, R. Materiais didáticos no ensino de línguas. In: MOITA LOPES, L. P. (Org.). Linguística aplicada na modernidade recente: Festschift para Antonieta Celani. São Paulo: Parábola, 2013. p. 163-195. . Livro em sala de aula: modo de usar. In: Materiais didáticos: escolha e uso. Programa salto para o futuro. Boletim 14. ago. de 2005.

SOARES, M. B. Português na escola: história de uma disciplina curricular. In: BAGNO, M. Linguística da norma. São Paulo: Edições Loyola, 2004. p. 155-177. ; CUNHA, M. A. A; NASCIMENTO, M; ALVARENGA, D. Ensinando comunicação em língua portuguesa no 1o grau: sugestões metodológicas, 5a à 8a séries. Rio de Janeiro: DEF/FENAME/UFMG, 1979.

TRAVAGLIA, L. C. Gramática e interação: uma proposta para o ensino de gramática no 1은 e 2 ㅇ graus. 2 ed. São Paulo: Cortez, 1997.

VALENTE, Cesar. Chora mais quem pode menos. In: KRIEGER, M. L. R. Comunicação e expressão através do conto e crônica. Florianópolis: Lunardelli, 1976. p. 15. 
VOLOCHINOV, V. N. Marxismo e filosofia da linguagem. Tradução de Sheila Grillo e Ekaterina Vólkova Américo. São Paulo: Editora 34, 2017 (1929).

Recebido em 26 de abril de 2018.

Aceito em 13 de maio de 2018. 